\title{
UNA REFORMA DEL ESTADO INDISPENSABLE, ENTRAMPADA POR LA PARTIDOCRACIA Y LOS PODERES FÁCTICOS
}

Jorge Alonso Sánchez

\section{Propuesta integral en el año 2000}

$\mathrm{E}$ n México las elecciones presidenciales del año 2000 implicaron la configuración de una importante alternancia en el poder. Después de siete décadas llegó a la Presidencia de la República un candidato que no pertenecía al viejo partido de Estado. Se dijo que se había dado una transición votada y no pactada, ${ }^{1}$ pero para que culminara la transición a la democracia se requerían nuevas bases y una profunda reforma del Estado.

Comandada por Porfirio Muñoz Ledo, en el segundo semestre de 2000 se integró una comisión para formular una propuesta que tuviera como fin la reforma del Estado. Hubo varios grupos de trabajo constituidos de manera muy plural por personalidades renombradas de la academia, de organizaciones sociales y de ámbitos políticos. ${ }^{2}$ Las conclusiones de este esfuerzo fueron entregadas al gobierno en $2001{ }^{3}$

Se planteó que había que llegar a la formulación de una nueva constitución. ${ }^{4}$ No existía ninguna experiencia contemporánea de cambio democrático exitoso que no incluyera una nueva constitucionalidad. La era globalizada obligaba a un replanteamiento de la responsabilidad del Estado mexicano ante esta situación. La nueva constitución tenía que dar instrumentos para que México cumpliera con sus responsabilidades globales. Obligaciones internacionales ineludibles para México son la promoción y protección de los derechos humanos, del medio ambiente y de los recursos naturales. Se vio como urgente avanzar hacia un cambio de régimen que garantizara la gobernabilidad. Se discutió la conveniencia de pasar de un sistema presidencialista hacia uno semipresidencial. Se propuso examinar la figura de Jefe de Gabinete, el cual sería ratificado por el Congreso, aunque el Presidente conservaría la facultad de remoción del mismo. ${ }^{5}$ Punto nodal fue el relativo a la transparencia en la información entre los poderes y hacia los ciudadanos. No se pretendía un poder ejecutivo débil, sino tres poderes fuertes que cumplieran con eficiencia y eficacia sus funciones para lograr un auténtico estado democrático de derecho. En esta forma se propuso que concurrieran las dos Cámaras para la aprobación del presupuesto federal — hasta ahora es facultad exclusiva de la Cámara de Diputados - y para la aprobación de tratados internacionales - competencia reservada a la Cámara de Senadores- - Se consideró conveniente que entre las facultades del Congreso estuviera la de promulgación 
de leyes si, pasado determinado tiempo, el presidente de la República no lo hacía.

Con la composición plural de fuerzas en el país el poder judicial ha ido cobrando relevancia, aunque los mecanismos existentes para designarlo no favorecen su autonomía. Se trata de un poder muy desprestigiado que habría que revalorarlo por medio de una limpieza en su composición, por una eficiencia en su ejercicio y erradicara la corrupción. Se planteó el fortalecimiento de la Suprema Corte de Justicia de la Nación; la elección de sus miembros se daría mediante un procedimiento democrático que asegurara su estabilidad, imparcialidad y carácter federativo. Se propuso la constitución de una defensoría del ciudadano como organismo que asesorara y patrocinara a los ciudadanos en defensa y ejercicio de todos sus derechos. Se ha detectado que está ausente un marco normativo acorde con la realidad delictiva, que falta capacitación y profesionalización de los servidores públicos, que existe una preocupante dilación en la aplicación de la justicia, una ausencia de protección a las víctimas, un enorme abuso del poder, y que prevalece la penalización de la pobreza. Para remediarlo se constató que había que realizar una profunda reforma al sistema de procuración de justicia. Las leyes y los procedimientos penales han de reformarse en el sentido de que el delito sea costoso para el victimario y no para las víctimas ni la sociedad. La reparación del daño debe ser un elemento de primer orden en las necesarias reformas.

Punto central para lograr la reforma del Estado es un efectivo federalismo. Se vio como ineludible la promoción de una Convención Nacional Fiscal que estableciera criterios para la redistribución de las fuentes contributivas y devolver potestades tributarias a los estados y municipios. Habría que estimular la contribución en la generación de recursos adicionales complementada con fórmulas de equilibrio fiscal.

El tema de las autonomías debe responder al reclamo de autonomías indígenas de acuerdo con el
Convenio 169 de la Organización Internacional del Trabajo. También se debe legislar en el ámbito constitucional la existencia de áreas de gestión con un alto grado de autonomía respecto a los tres poderes. Estas áreas podrían constituirse como consejos, comisiones o institutos encargados de regir espacios como las autonomías indígenas, la cultura, la educación, las Iglesias, los medios de comunicación, los procesos electorales o los impuestos.

Se ha considerado lo relevante de que haya varios organismos autónomos estatales - ahora existe un organismo electoral y una comisión de derechos humanos-. Éstos deberían responder ante el poder legislativo. Debido a que un cambio de régimen implica el esclarecimiento del pasado se propuso una comisión de verdad que averiguara y transparentara delitos graves en materia de derechos humanos. Su facultad sería declarar lo que sucedió. Estaría conformada por el poder legislativo, e integrada por elementos de la sociedad civil e instancias públicas. Su función sería analizar y ponderar las faltas graves contra el patrimonio de la Nación y los derechos humanos. ${ }^{6}$

Demanda básica en el punto relativo a los derechos humanos es que se garantice la exigibilidad de todo derecho fundamental por medio de leyes que reglamenten su cumplimiento. En esta materia se ha propuesto que se tiene que establecer la supremacía de los tratados internacionales de derechos humanos frente al derecho interno. Se ha detectado que la autonomía que concede la Constitución a los organismos de derechos humanos se encuentra limitada por la forma como se designan a los presidentes e integrantes de estas comisiones.

Se ha propuesto que, siguiendo el método de designación recomendado por las Naciones Unidas, se logren representaciones pluralistas de las fuerzas sociales, sin que se interprete como un reparto de cuotas entre los partidos. Entre los derechos que estas comisiones deberían contemplar están los económicos 
y sociales — trabajo, alimentación, vivienda, salud y educación-, así como los ambientales, los culturales y los de los migrantes. También se han de buscar mecanismos para fortalecer las recomendaciones de los organismos protectores de los derechos humanos.

Las organizaciones de la sociedad civil han insistido en una adecuada reglamentación. Estas organizaciones cumplen importantes tareas sociales en lo asistencial, en la promoción, en la participación ciudadana, en la generación de empleos, en la atención a problemas a los que no llega el gobierno, y en la intermediación entre sociedad y éste. El nuevo marco jurídico debería prever la participación de tales organismos en los procesos públicos y apoyos que les pudiera brindar el Estado. En la legislación podría plantearse que fueran reconocidos como instituciones de interés público, y se tendrían que marcar los requisitos mínimos para su constitución, así como el establecimiento de sus derechos y obligaciones. Habría que buscar una simplificación administrativa, no discrecional, para el reconocimiento de estas organizaciones. También se debería ver la creación de un registro nacional autónomo que las considerara.

Un punto que desde una reforma política realizada en 1977 ha quedado pendiente es el relativo al derecho a la información total. Con las profundas transformaciones del fin del siglo pasado e inicios del presente las reformas relativas a cuestiones de información resultan apremiantes. Se ha hecho ver que el artículo sexto constitucional garantiza la libertad de expresión, mientras que el séptimo refiere a la libertad de imprenta. Estos artículos vienen del siglo antepasado, cuando las modificaciones más importantes en el cambio del siglo xx al xxi tienen que ver con la nueva era de la información. Se ha planteado que la libertad de expresión debería implementarse como un derecho individual que establece una obligación de no hacer del Estado, mientras que el derecho a la información es un derecho social que implica un deber hacer para el Estado.
Se propone trasladar y desarrollar el derecho a la información en un solo artículo constitucional, mientras que en otro se agruparían las libertades de expresión y de imprenta. Se han desglosado los contenidos que debería contemplar el precepto constitucional que regulara el derecho a la información. Se tiene que garantizar este derecho y obligar a la transparencia estatal. ${ }^{7}$ Los poderes públicos deben estar obligados a dar a conocer la información de los asuntos de su competencia y los datos de la realidad mediante un órgano autónomo.

A los individuos se les tiene que garantizar la información que el Estado tenga sobre sus personas, y en su caso rectificarlas. El Congreso de la Unión expediría una ley de archivos públicos que definiera las competencias federal, estatal y municipal sobre esta materia. Las tareas de acopio, resguardo y difusión de los archivos se tienen que considerar como una función estatal que también se encomiende a un órgano autónomo. Se propone que la ley determine la publicidad de los archivos sin más limitaciones que las establecidas en su texto en vista del interés nacional.

En esta temática también es indispensable prohibir el uso de recursos públicos para la propaganda de los gobernantes. Por su parte, la ley constitucional de garantías de la libertad de expresión y del derecho a la información debe contener la explicitación de los derechos de los profesionales de la comunicación: respeto a la integridad del trabajo, la cláusula de conciencia, el secreto profesional de fuentes de información y el salario profesional. Por otro lado también debe precisar los derechos de los ciudadanos de acceso a la información, réplica, rectificación y aclaración. Se debe crear un órgano autónomo para proteger estas libertades fundamentales y de derechos humanos. Por su parte el Estado tiene que garantizar el ejercicio real del derecho a la información mediante la regulación de los archivos públicos. 
Se plantea la creación de un órgano autónomo responsable de ello, y un sistema nacional de archivos. Se apunta que se tienen que fijar los criterios de desclasificación de documentos oficiales, a través de una comisión del Congreso. También hay que prever sanciones a los servidores públicos que oculten o destruyan archivos públicos. Se ha propuesto además un nuevo fundamento constitucional que contemple lo relativo a radio y televisión. El régimen de radio y televisión también debería quedar a cargo de un organismo autónomo. En todo esto hay que remar contra corriente, por muchos años se fomentaron mecanismos de censura e intervencionismo gubernamental en los medios de comunicación y se estimularon poderosos grupos económicos - principalmente en los medios electrónicos — que han alentado el autoritarismo, el oficialismo y la manipulación informativa. Entre esos mecanismos un lugar preponderante lo ocupa el manejo discrecional para la operación de estaciones de radio y televisión, con lo que se ha fomentado una fuerte complicidad entre concesionarios y gobierno. El organismo propuesto debería ser constitucional, con participación ciudadana responsable de regular todos los sistemas de comunicación a distancia y de otorgar los permisos y autorizaciones teniendo en cuenta el interés general. ${ }^{8}$

Entre los derechos económicos y sociales urge defender el derecho a la educación pública, laica y gratuita. El Estado tiene la obligación de garantizar la igualdad de oportunidades para todos en todos los niveles educativos. La educación impartida por el Estado debe garantizar la libertad de expresión y de conciencia. Hay insuficiente gasto educativo y deficiente atención a la demanda. Hay baja calidad en la enseñanza y graves desequilibrios regionales en este referente. El gasto público en educación se tiene que incrementar.

Otros de los derechos necesarios de salvaguardar son los del empleo y salario justo. Es fundamental la recuperación de los salarios y la competitividad de las empresas. Se deben crear empleos suficientes para responder a la legítima demanda de un empleo digno. Se tiene que elevar la productividad. Empresarios y gobierno tienen la obligación de buscar la generación de empleos productivos. Se debe promover el desarrollo rural integral para mejorar las condiciones de vida. El campo mexicano se encuentra devastado. Si no se atiende se convertirá en un polvorín. No es viable que prosigan condiciones que marginen a gran parte de la población económicamente activa. La pobreza hay que erradicarla a través de la incorporación productiva de la mano de obra. Las reformas constitucionales en materia laboral no pueden eludir una consulta democrática nacional. En este rubro hay que destacar la necesidad de tener en cuenta los derechos internacionales laborales. Ya no se puede relegar el derecho que tienen los trabajadores a organizar libremente sindicatos para la defensa de sus intereses. En lo laboral se requiere un nuevo acuerdo social entre empresarios, trabajadores y el Estado. En este nuevo pacto se abandonarán las formas corporativas para llegar a sustentarse en la democracia, en la libertad y autonomía de las organizaciones representativas, en la transparencia administrativa de las instituciones, en la honestidad profesional de los funcionarios y en la intolerancia hacia la corrupción. No puede aplazarse por más tiempo la existencia de una estructura sindical libre, autónoma y democrática. Tiene que contemplarse una revalorización del trabajo y del trabajador. Hay que acordar las nuevas reglas que permitan acotar la conflictividad laboral y evitar que se mezcle con intereses políticos.

La normatividad de la política migratoria es atrasada y no contempla lo que ya ha suscrito México en tratados internacionales. Hay que llegar a que se garantice la bilateralidad de las políticas migratorias, a incluir los temas de la movilidad de los trabajadores y sus garantías laborales. Debe quedar salvaguardado el derecho al libre tránsito de las personas a través de las fronteras en el marco de acuerdos bilaterales y multilaterales. Se tienen que defender los derechos individuales, civiles, 
laborales, culturales y políticos de los mexicanos en el extranjero.

No se pueden dejar de lado los derechos ambientales. Se debe recoger y regular constitucionalmente el concepto "sustentabilidad" para asegurar la continuidad de la biosfera y proveer a las generaciones futuras un ambiente sano.

La reforma del Estado también debe incluir un capítulo concerniente a la democracia representativa y a la representación política. De hecho en esta última es donde más avances ha habido, aunque también han quedado muchos pendientes. Se pretende que se incorporen en la Constitución federal y en las locales las modalidades de plebiscito, referéndum, iniciativa popular, consulta ciudadana, audiencia pública, colaboración social e instancias de quejas y denuncias. Tema clave es el fortalecimiento de los órganos electorales. Existe la propuesta de una federalización de la materia electoral, pues muchas legislaciones locales dependen de los intereses políticos de los gobernadores, y en no pocos casos las autoridades electorales locales se encuentran sometidas al arbitrio de caciques. Habría que incrementar la fiscalización sobre ingresos y gastos de los partidos políticos. Constituye uno de los graves pendientes. Otro punto que de igual manera ha sido debatido es el concerniente a la segunda vuelta en las elecciones para los cargos de los poderes ejecutivos, en particular para el caso de la Presidencia de la República. Muchos debates han suscitado lo relativo a la no reelección. Se ha aceptado que prosiga en la Presidencia de la República, pero no para los senadores, diputados y presidentes municipales. La reelección inmediata fortalecería al poder legislativo frente al ejecutivo federal, y a los municipios - en estos últimos se ha visto la conveniencia de la ampliación del periodo de gobierno.

Otro tema discutido considera los calendarios electorales. Dada su dispersión, los partidos siempre se encuentran en algún proceso electoral, lo cual ha determinado un obstáculo en el entendimiento entre partidos y para la formación de consensos mínimos que estimulen un mejor desempeño gubernamental. Otro problema ha sido la extensa duración de campañas que repercute en derroche innecesario de recursos y en un cansancio de la población que se satura de temas electorales. Se ha propuesto reducir el periodo de las campañas electorales y homologar los calendarios de las elecciones con el fin de que se desarrollen las municipales, estatales y federales de manera conjunta. El problema de la compra y coacción del voto prosigue. Se ha criticado fuertemente el uso de recursos públicos y la utilización de conductas clientelares que favorecen las campañas empleadas por los gobiernos hacia los postulantes de sus partidos. Se dispone del aparato gubernamental, de su estructura administrativa, de sus medios propagandísticos, y de sus recursos económicos para beneficiar a determinados candidatos, lo cual impide que la competencia electoral sea equitativa ya que se hace uso indebido del erario público. Se ha visto que el cumplimiento de las obligaciones normales de un gobierno puede convertirse en una fuente de manipulación política al privilegiar ciertas acciones de gobierno en los tiempos electorales. Se ha demandado que no se haga proselitismo en favor de partidos y candidatos y en contra de otros por medio de programas de gobierno. La propuesta es establecer una prohibición absoluta a toda autoridad para que por medio de sus programas de gobierno se haga proselitismo electoral. Consecuentemente tienen que impedirse las campañas de propaganda del actuar gubernamental en tiempos electorales.

Se ha constatado que las causales previstas por la legislación electoral no resultan tan graves como la comisión de un delito en esa materia. Hay una incongruencia, pues mientras la sanción de los delitos se dirige al sujeto responsable no se afecta la votación. Las causales de nulidad vigentes al ser comparadas con los 
delitos resultan ser menos gravosas. Se exige que se establezcan instituciones y reglas que den plena confianza y certeza en la procuración de justicia electoral. Por esto mismo se propone que la fiscalía especial para delitos electorales tenga autonomía y no guarde dependencia del ejecutivo. El titular de esa fiscalía debería ser designado por la Cámara de Diputados. Se demanda que se revisen los tipos penales electorales que pueden constituirse como causales de nulidad en las votaciones.

Se sabe que un nuevo marco legal por sí mismo no bastará para las transformaciones que el país necesita. Se requiere un gran esfuerzo de convergencias sociales y políticas, y una manera nueva de hacer política. Pero sin un sustento legal avanzado las limitaciones serán mayores. Entre los pendientes se encuentra el perfeccionamiento de las instituciones de la democracia. En particular conviene que la democracia no sea tan costosa. El poder legislativo requiere de encontrar los mecanismos para realizar un trabajo eficiente que no quede como rehén de los problemas entre los partidos.

El poder judicial tiene que ser revisado a fondo para que consiga la confiabilidad deseable en los momentos actuales. Mientras existan los altos índices de delincuencia y de impunidad, mientras persista el fortalecimiento del crimen organizado - de manera particular en el narcotráfico-, y mientras prosiga la evidente complicidad entre responsables de la seguridad pública y las mafias criminales, la vida democrática seguirá en peligro. La reforma municipal también es otro de los graves pendientes que evita sea una realidad la demanda del municipio libre, con recursos suficientes para una operatividad eficiente.

Los poderes constituidos han demostrado una alta capacidad para sacarle la vuelta a obligaciones democratizadoras. Hay muchas formas que pueden ejercerse para burlar el voto libre y mantener indebidas ventajas electorales. Se tienen que conseguir elecciones libres, transparentes y equitativas en los comicios federales y locales. También el ejercicio del poder tiene que democratizarse. Los ciudadanos requieren que los poderes rindan cuentas, que abran espacios para la participación en la elaboración de programas y su seguimiento. Se pide transparencia, soluciones concretas, eficaces, ante necesidades específicas. Hay mucho que hacer en la rendición de las cuentas y en la urgencia por considerar verdaderamente a los ciudadanos. Los poderes deben ser realmente responsables. En la tarea de democratizar la democracia se encuentran los retos de democratizar a los poderes económicos y a la opinión pública. ${ }^{?}$

\section{El intento de 2001}

Enfatizando que ningún partido político tenía la mayoría necesaria para decidir por sí solo el desahogo de los asuntos de la Agenda Nacional, a finales de 2001 el presidente Fox y los presidentes de los partidos políticos suscribieron un acuerdo nacional en el que hicieron un compromiso para avanzar en una propuesta de reforma del Estado. Sin embargo, fue criticado por dejar fuera temas sustanciales y por no ser sino el enunciado de carencias sin que se señalaran propuestas concretas de solución. Se fue manifestando otro malestar entre no pocos ciudadanos por el hecho de que el poder legislativo no tenía contrapesos políticos eficaces y porque no se mostraba responsable ante los ciudadanos durante su gestión. Finalmente dicho pacto no trascendió el acto de la firma, precisamente porque los partidos tenían en mente no la cooperación sino la contienda en pos de la presidencia de la República en 2006.

El partido del ejecutivo estaba en minoría. Faltaban alicientes para que los diputados integrantes de los otros partidos llegaran a acuerdos. Se privilegiaba la pugna política con el fin de alcanzar posiciones de poder. Se exacerbó la partidocracia de espaldas a las necesidades nacionales. En las elecciones de 2003 se expresó el 
descontento ciudadano por medio de una alta abstención. Los partidos no entendieron la lección y prosiguieron en una dinámica inmediatista que respondía a los intereses de las burocracias partidistas. Los supuestos organismos autónomos fueron partidizados en la composición de sus instancias directivas. Se fue dando una degradación. Era evidente que el viejo régimen seguía imperando y ya no era funcional. Fuera de declaraciones no había acciones para poner remedios. Existían muchos problemas como la cuestión fiscal que no eran atendidos. Además la reforma electoral que había propiciado elecciones confiables en 1997 y en 2000 estaba sobrepasada y resaltaban sus grandes carencias. En las precampañas y campañas electorales se combinaban el dinero en exceso - y mal habido - con una vacía mercadotecnia política, lo cual sólo hacía ganar a manos llenas a los dos oligopolios televisivos. Esto repercutía en el malestar con una democracia electoral que no sólo no resolvía los grandes males nacionales, sino que se había convertido en otro de los graves padecimientos políticos. No obstante que el diagnóstico era patente, los partidos no querían poner las soluciones legales oportunas. Se adelantaron las precampañas presidenciales y la situación empeoró.

\section{Proliferación de discusiones en torno a la reforma del Estado}

Durante los primeros años del siglo XxI se ha dado una gran cantidad de discusiones académicas y políticas sobre la urgencia de una reforma del Estado en México. Se constató que las normas impuestas por el denominado Consenso de Washington habían colocado las bases de una crisis de gobernabilidad. Los ajustes estructurales limitaron al Estado y generaron nuevas contradicciones. ${ }^{10}$ La deuda externa tenía hipotecado al país. Había crecido la desigualdad y empeorado la inseguridad. La economía se encontraba dependiendo de impredecibles mercados financieros. Se agravó la pobreza y se quebraron las redes sociales de protección contra la adversidad. Se había incrementado la insatisfacción respecto de los políticos. Gran parte de la población se mostraba frustrada. Urgían reformas para convertir a los partidos en instituciones responsables. ${ }^{11}$ En el contexto de estas discusiones, en 2004 el Congreso y la Facultad de Derecho de la UNAM organizaron una reunión académico-política en la que abundaron una vez más las propuestas sobre la reforma del Estado. Pero este esfuerzo no transcendió la publicación de las memorias de ese evento. Los partidos decían estar interesados, aunque no quisieron pasar a los hechos.

Porfirio Muñoz Ledo, presidente de la Fundación Nacional para la Reforma del Estado, ha insistido en la necesidad de abolir ese régimen presidencial que ha sido la conjunción del caudillismo latinoamericano con rasgos de presidencialismo anglosajón. Propuso un sistema donde el Estado se diferenciara del gobierno. El jefe del Estado no debía ser al mismo tiempo el jefe de Gobierno. Esto implicaría pasar a un sistema semipresidencial. ${ }^{12}$ El secretario de Gobernación, Santiago Creel, afirmó que en México no se había dado un momento fundacional para la transición. Aunque en la práctica se hubiera constatado que el régimen presidencial ya no operaba, nada se hacía al respecto. Se vivía en un sistema presidencial que en los hechos se encontraba parlamentarizado debido a un gobierno dividido. Creel también proponía flexibilizar el sistema presidencial para poder enfilar hacia un modelo semipresidencial que permitiera crear mayorías entre el ejecutivo y el congreso. Lo lamentable era que en la situación que se estaba viviendo no existían incentivos para formar esas mayorías. ${ }^{13}$ Pero la actuación del secretario de Gobernación, quien no ocultaba su pretensión de ser candidato presidencial, no pudo conseguir los acuerdos indispensables. 


\section{La propuesta de Alianza Cívica}

Las desbocadas precampañas presidenciales hacían ver que habría que poner diques al dinero y a los medios de comunicación electrónica. Una organización ciudadana que jugó un papel preponderante en el avance democratizador de la década de 1990, Alianza Cívica, volvió a la palestra. Propuso una nueva reforma electoral. En primer lugar que hubiera una ley de partidos políticos que regulara sus vidas internas, $y$ ofreciera mecanismos de transparencia y rendición de cuentas. Punto fundamental era el relativo a la fórmula de financiamiento público a partidos políticos, que aumentaba exponencialmente este financiamiento, con lo que convertía a las camarillas partidarias en entes enriquecidos en medio de un pueblo empobrecido y con altas carencias. ${ }^{14}$ Era un imperativo y demanda general que se redujera sustancialmente el financiamiento - tanto público como privado- para las elecciones. Otro renglón apuntaba a una férrea y eficaz fiscalización del financiamiento de los partidos. La antigua ley no regulaba las precampañas. Ahora era indispensable hacerlo. Lo mismo que recortar su tiempo. El hecho de que durante todo el sexenio en algún lugar hubiera campañas electorales impedía los acuerdos entre los partidos e impulsaba el pleito. Para evitarlo se propuso la compactación de los calendarios electorales. El organismo electoral federal había sido una pieza clave en la confiabilidad de las elecciones de 1997, 2000 y 2003. Pero como los partidos habían partidizado su composición, esto ponía en riesgo las elecciones de 2006. Por eso mismo la propuesta tocaba el punto de cómo no partidizar la elección del consejo general del organismo electoral federal. Desde 1996 estaba en la legislación el derecho de los mexicanos que se encontraran en el extranjero de votar por el presidente de la República. Esto no se había reglamentado. Alianza Cívica planteó otorgar al organismo electoral federal facultades como el único responsable de organización del ejercicio del voto de los mexicanos residentes en el extranjero, y garantizar el mantenimiento de un registro permanente de los mismos. ${ }^{15}$ Aunque parte de lo último fue aprobado en la Cámara de Diputados, el Senado sólo aceptó una modalidad cuestionada y nada segura del voto por la vía postal.

\section{Búsquedas fracasadas en 2005}

Antes de dejar la Secretaría de Gobernación para ir a gastar millonadas en su precampaña, Santiago Creel planteó una negociación con los tres principales partidos para lo que llamó una transición pactada. Se trataba de examinar una reforma de "coyuntura" que comprendiera la regulación de precampañas y el acceso de los partidos a medios de comunicación. A finales de mayo de 2005 ya existía un predictamen sobre reformas a la legislación electoral que normaba precampañas y gastos en radio y televisión. Pero se necesitaba aprobar antes del primero de julio de ese año para que pudiera entrar en vigor en el proceso electoral de 2006.

En junio se reunieron en Zacatecas representantes de las organizaciones de alcaldes, congresos locales, institutos electorales y tribunales electorales para promover una segunda generación de reformas electorales que garantizaran la legitimidad de los comicios de 2006. Hubo críticas al doble lenguaje de los principales actores políticos. Al final se adoptó una declaración que fue titulada El espiritu de Zacatecas. Se urgía a aplicar reformas desafiando las inercias y los estrechos intereses de los partidos. Tema central fue la limitación de la influencia del dinero en los procesos electorales. Había que reglamentar las precampañas, reducir los topes y acortar los tiempos. También se tendrían que dar más facultades fiscalizadoras al organismo electoral y reformar lo relativo a tiempos de radio y televisión para fines electorales. Se aceptó la necesidad de crear una ley de partidos que regulara sus quehaceres internos. Había que acabar con la simulación 
de autonomía en los organismos electorales pues se conformaban con cuotas partidistas. ${ }^{16}$

En otra reunión sobre reforma del Estado que se dio a mediados de junio en Pátzcuaro, se exhortó que se realizaran las reformas electorales, cuando menos para controlar los gastos de radio y televisión, pues de lo contrario se abrirían de nuevo las compuertas de la sucesión a la influencia desorbitada del poder del dinero y sobre todo del dinero ilícito. Se acusó a los partidos que no querían reducir los recursos de las campañas. Se volvió a proponer que fuera el organismo electoral el encargado de pagar y contratar a los medios de comunicación con lo que podría fiscalizar mejor los tiempos partidarios. Pero como la situación imperante redituaba muchas ganancias a los dueños de los grandes medios electrónicos colocó a éstos en una férrea oposición ante cualquier cambio en la mencionada materia.

A mediados de junio se contaban siete iniciativas pendientes de dictamen en la Cámara de Diputados sobre la regulación de las precampañas. Había consenso en que el gasto excesivo en las precampañas condicionaba todo el proceso. En ese momento destacó que los diputados, reconociendo que las reformas electorales eran urgentes y necesarias, no las hicieron. Dejaron el espacio libre para gastos excesivos y evitaron los controles. Hubo mala conciencia. Se propiciaron precampañas desbocadas y una danza de los millones de pesos, sin que legalmente se pudiera detectar su origen. Tampoco se modificaron tiempos ni capacidades para la fiscalización. El modelo aceptado por los partidos para sus precampañas y campañas electorales favorece aún más a los poderes fácticos del dinero y de los medios electrónicos. ${ }^{17}$ Porfirio Muñoz Ledo consideró que México se acercaba a una transición en fracaso porque los partidos no habían querido hacer las reformas necesarias para consolidar la democracia. Pesimistamente veía que ahora la urgencia consistía en impedir el entierro de la transición. ${ }^{18}$
Pese a que no se logró ni una limitada reforma electoral, sigue siendo necesaria la profunda reforma del Estado. El ex presidente de Brasil, Fernando Cardoso, declaró que México requería una profunda reforma de todo el aparato de gobierno con el fin de que tuviera un mayor enlace con la sociedad. ${ }^{19}$ En un encuentro donde hubo una participación plural de representantes gubernamentales y de organismos de la sociedad civil se discutió el régimen político, las nuevas relaciones Estado-sociedad para una democracia sustantiva, el nuevo pacto económico y social por el que desde abajo se lucha, la reforma electoral que la sociedad exige, la participación ciudadana en la formulación de las relaciones de México con el exterior, y la soberanía de la nación. Se vio que había peligro de una involución democrática y hasta de una regresión autoritaria. Se constató que México se estaba trasladando de un Estado débil a uno fallido. La desilusión provocada por una transición que se había quedado a medio camino y que había fortalecido una partidocracia se estaba traduciendo en un peligroso desencanto hacia la democracia. Se recalcó que un Estado de derecho era aquel en que los diferentes poderes públicos estaban supeditados a la ley. Si el Estado era débil cedería ante las presiones de los poderes fácticos. Se pronunciaron por la consolidación de un Estado social. Varios ponentes demandaron una reforma al sistema de procuración de justicia en México. Se propuso que la sociedad civil realizara un monitoreo y fiscalización de las precampañas y campañas de los partidos, y que también se constataran las cuotas de equidad de género en las candidaturas titulares de los partidos. Fueron debatidos muchos temas como el incremento de la desigualdad, los graves índices de inseguridad, la precaria gobernabilidad, la corrupción, la entrada de dinero sucio a la política, la utilización de la justicia para desacreditar al contrincante, etc. Todo eso ponía en riesgo la viabilidad de México como Estado soberano. Se hicieron señalamientos acerca del 
estancamiento económico, la creciente dependencia, el desmantelamiento de sectores importantes de actividad productiva, la contracción de los salarios y del mercado interno. Se hicieron llamados hacia la construcción de un Estado social democrático sustentado en la diversidad y pluralidad. Se criticó el abismo existente entre la clase política y la sociedad. Se planteó la necesidad de una movilización civil autónoma sin la cual no se preveía que se pudiera llegar a una auténtica reforma del Estado.

Esas discusiones lograron desembocar en acuerdos, los cuales se plasmaron en la Declaratoria Ciudadana de Pátźcuaro. Se acordó enarbolar como bandera unificadora del movimiento ciudadano la reforma del Estado mexicano y una refundación constitucional de la República. En lo inmediato habría que garantizar un relevo ordenado y democrático en las elecciones presidenciales de 2006. Acuerdo importante fue el relativo al impulso de reformas institucionales y jurídicas de mediano y largo plazo que, siendo fruto de un nuevo pacto político, garantizaran e hicieran perdurar la gobernabilidad democrática por medio de políticas públicas capaces de resolver los más ingentes problemas nacionales. Los participantes compartieron el convencimiento de que la reforma del Estado era una premisa básica para la viabilidad de México como nación. Se tendría que avanzar en las reformas económicas y sociales necesarias para combatir con eficacia la pobreza y la desigualdad. Se debía elevar la capacidad competitiva de la economía para ampliar los horizontes del desarrollo. La reforma del Estado involucraba la redefinición de las relaciones entre el Estado y la sociedad, y era un prerrequisito para ampliar y potenciar la incidencia ciudadana en la discusión, diseño e instrumentación de las estrategias del desarrollo nacional. Además de la premisa de gobernabilidad, la reforma del Estado también era fundamento e instrumento del desarrollo económico y social.
Sin embargo no había ingenuidad. Los participantes eran conscientes de que, pese a la trascendencia y urgencia de la reforma del Estado, en la coyuntura de 2005 y 2006 no existían las condiciones políticas idóneas para concretar dicha reforma. Vieron que para llegar a la reforma diversos agentes sociales tenían que emprender una acción que concienciara tanto a la clase política como a una gran parte de la población. En esta ardua empresa las organizaciones de la sociedad civil podían ser un factor impulsor de consolidación democrática, del ensanchamiento de los cauces de desarrollo nacional y de la definición de un proyecto de nación. Para impulsar la reforma del Estado resultaba indispensable aglutinar acciones y voluntades democráticas que en ese momento se encontraban dispersas. Habría que llegar a la definición de una agenda, de una perspectiva ciudadana para la ansiada reforma, rescatando puntos de vista locales nacionales y globales que se propusieran el tránsito de una democracia meramente representativa y procedimental a una democracia participativa y deliberativa. ${ }^{20}$ El Programa de las Naciones Unidas para el Desarrollo llamó en ese encuentro a no dejar los cambios sociales al azar. El PNUD ha hecho ver que el desapego ciudadano hacia la democracia en América Latina se debe a que la democracia electoral no ha podido resolver los graves problemas de pobreza y desigualdad; $y$ ha propuesto como salida una democracia integral en donde se combinen la democracia electoral, la política, y de manera importante la social. ${ }^{21}$

A finales de septiembre de 2005, cuando los partidos se encontraban en pugnas internas para la designación de su respectivo candidato presidencial, se lograron algunos acuerdos en los que de alguna manera se tocaban las temáticas de la reforma del Estado. El incansable promotor de esa reforma, Porfirio Muñoz Ledo, al frente de su Asociación Nacional para la Reforma del Estado convocó a los presidentes de los partidos políticos para iniciar una ronda de negociaciones al respecto. ${ }^{22} \mathrm{Se}$ 
formó una Coalición Social Ciudadana para la Transición Democrática con Justicia y Equidad integrada por una gran variedad de líderes políticos y sociales que se propusieron diseñar una propuesta nacional que mirara más allá de las fechas electorales de 2006. También a finales de septiembre de 2005 los principales empresarios con otros dirigentes sociales firmaron un Acuerdo Nacional para la Unidad, el Estado de derecho, el Desarrollo, la Inversión y el Empleo. En este último documento compuesto por cinco grandes apartados —Estado de derecho y seguridad pública, desarrollo con justicia, formar y desarrollar capital humano y social, desarrollo de capital físico, y reforma de la administración pública - había varios puntos que tenían que ver con el tema que nos ocupa. En materia electoral retomaba las propuestas de reprogramación de los calendarios políticos para evitar la excesiva dispersión de los procesos electorales, revisar la duración y el financiamiento de las campañas y de las precampañas, y asegurar la transparencia en el uso de los recursos. En conjunto ese acuerdo pretendía el fortalecimiento de la unidad nacional y el establecimiento de políticas de Estado y objetivos de mediano y largo plazos. ${ }^{23}$ Se ha destacado que este documento propicia el debate público. No obstante se han hecho señalamientos de sus graves deficiencias. Se ha dicho que omite cualquier mención a las reformas que aseguraran una mayor autonomía del Estado respecto de los poderes fácticos. Se le critica que conmine a la aceptación acrítica de los resultados electorales en vez de exigir plena legitimidad del proceso, que todos los actores se comporten de acuerdo con la legalidad. Entre las omisiones también se encuentra que no dice cómo podrían los poderes públicos hacer frente a las responsabilidades que se les asignan a falta de mayorías políticas y de un andamiaje constitucional diseñado para la eficiencia democrática. Se le critica que no aborde el grave problema de la desigualdad. Se demanda que las propuestas surjan de un diálogo plural y no de intimidación, veto o ultimátum de poderes reales.
Se llama la atención sobre el peligro de que la división de poderes sea suplida por el duopolio del poder financiero y del poder mediático instalado sobre la docilidad del estamento político. Una verdadera democracia no puede aceptar recetas unilaterales por parte de los poderes económico y mediático. ${ }^{24}$ En el documento del grupo más rico del país son perceptibles los tonos del Banco Mundial y del Banco Interamericano para el Desarrollo; lo que no está dicho resulta más importante que lo explícito. Se le achaca una concepción limitada y completamente instrumental de la dimensión del Estado. Se demandan políticas de Estado pero nunca se delimita su contenido ni significado. Se hace ver que la mirada empresarial sobre el Estado se reduce a una reforma administrativa. Se habla de Estado de derecho, pero nada se dice respecto a la urgente reforma del Poder Judicial. Nada hay sobre el Estado de derecho referido al espacio laboral en donde hay una creciente simulación de las relaciones entre el trabajo y la empresa. Tampoco se habla de la redistribución del ingreso en una sociedad polarizada. Los grandes medios electrónicos suscribieron el documento, pero se han opuesto a una ley que modernice y transparente las oscuras relaciones entre gobierno y los concesionarios. Finalmente el gran promotor, el multimillonario Carlos Slim ${ }^{25}$ nada dice de un organismo autónomo regulador de las telecomunicaciones. ${ }^{26}$ Muñoz Ledo criticó que el poder oligárquico creyera que bastaba por sí mismo para imponer patrones de conducta, así se pretendieran generosos, al resto de la comunidad nacional. ${ }^{27}$ Este documento más que cambios sustanciales de fondo parece que es un posicionamiento de los poderes fácticos ante quien resulte ganador de la contienda electoral de 2006.

Desde diferentes ámbitos se insta a que se promuevan cambios. Debido a que el anterior proyecto nacional ha perdido vigencia ha ido creciendo la concientización de la necesidad perentoria de definir uno nuevo con el concurso de actores económicos, sociales y políticos. La masa crítica en torno a la reforma del Estado se ha 
calificado como excepcionalmente rica y variada. ${ }^{28} \mathrm{El}$ sistema ya ha llegado a un grado que no puede proseguir como está. Pero los poderes fácticos por un lado y una partidocracia sometida a los intereses de éstos han impedido una reforma del Estado desde una perspectiva democratizadora de fondo.

Han surgido visiones que hacen planteamientos radicalmente diversos a los de los partidos y de los poderes fácticos. En la Sexta Declaración de la Selva Lacandona de mediados de 2005, el Ejército Zapatista de Liberación Nacional proclamó la necesidad de impulsar una lucha para hacer una nueva constitución y nuevas leyes que tomaran en cuenta las demandas del pueblo mexicano sobre techo, tierra, trabajo, alimento, salud, educación, información, cultura, independencia, democracia, justicia, libertad y paz. La nueva constitución debía reconocer los derechos y libertades del pueblo y defender al débil frente al poderoso. ${ }^{29} \mathrm{Hacer}$ eso implicaría una reforma del Estado. Pero la propuesta zapatista no contempla un diálogo con los partidos ni con las instituciones del Estado, sino que pretende lograr una construcción contundente desde abajo por medio de una discusión y acuerdos entre la inmensa mayoría de los depauperados, marginados y vapuleados por la política neoliberal imperante.

\section{Perspectivas divergentes en cuanto a tiempos, actores y sentido de una reforma del Estado}

Por una parte existe la percepción de que la posposición de la reforma va a deteriorar cada día más la situación política del país. Los partidos, encerrados en sus lógicas inmediatistas de alcanzar la Presidencia de la República, se van a encontrar que después de los comicios de 2006 se reproducirá el entrampamiento sufrido durante todo el sexenio foxista, porque es previsible que ninguna fuerza política obtenga una mayoría que le permita gobernar. Por eso se ha incitado a hacer los cambios necesarios antes de que el país se encuentre en la vorágine de las campañas. Pero ésta ya se ha instalado desde las precampañas electorales en las que impera el ambiente de la rivalidad y de la disputa y no del acuerdo más amplio. No obstante, persiste una tendencia que no pierde la esperanza de que los partidos pacten algunos cambios para el bien de la situación general.

Se van configurando dos grandes espacios para la construcción de consensos en torno a una reforma del Estado: el concerniente a la que deberían formular las elites, y el que se pretende configurar por medio de una amplia y larga consulta entre la gente de abajo que no se circunscribe a los límites de los tiempos electorales.

Hay planteamientos que llaman la atención acerca de no caer en ilusiones sobre los posibles alcances de una reforma del Estado. En esta tendencia prevalece la idea de que el Estado, siendo intrínsecamente parasitario y predador, es irreformable. Wallerstein cuestiona la idea general de que sea a través de las reformas del Estado, de esas reformas progresivas instrumentadas desde el aparato estatal, que se puedan ir resolviendo los problemas de las sociedades actuales. ${ }^{30}$ Se han hecho precisiones en el sentido de que hay reformas que consideran al Estado como Estadoempresario, y que las reformas que han imperado lo han convertido en algo complejo y contradictorio. En esta forma se llama la atención acerca de que el Estado débil auspiciado por el Consenso de Washington sólo es tal en lo que a las estrategias de hegemonía y confianza se refiere, pues en lo relativo a las estrategias de acumulación ese Estado ha demostrado tener más fuerza que nunca al legitimar en el espacio nacional las exigencias del capitalismo global. Ese Estado somete todas las interdependencias a la lógica mercantil. No obstante, ante las brechas que se han abierto frente al Consenso de Washington otros han propuesto una reforma del Estado como una articulación entre Estado y comunidad. Se trataría de la configuración de un conjunto de flujos, redes y organizaciones donde se 
combinarían e interpenetrarían elementos estatales y no estatales. El Estado aparecería como articulador que aseguraría las reglas de juego. Esta visión promueve la refundación democrática de la administración pública. Se trataría de una reinvención solidaria y participativa del Estado. Las preguntas surgen sobre el sujeto de la reforma, sobre los sectores de la sociedad que puedan impulsarla. ${ }^{31}$ Han aparecido precisiones como las formuladas por los investigadores del Estado en América latina Teresa Castro y Lucio Oliver. Ciertamente no habría que perder de vista el sentido de las reformas del Estado promovidas por el Banco Mundial para que los estados latinoamericanos se insertaran en una globalización neoliberal y que impulsaran la configuración de un Estado neoliberal en medio de una creciente privatización de los espacios públicos del Estado, ${ }^{32}$ en medio de la rapacidad de dirigentes financieros y la crisis de representación y participación popular. No obstante el horizonte de las reformas no se agotaría ahí. La crisis del neoliberalismo ha abierto una posibilidad de una reforma del Estado alternativa. Ésta debería ser democrática y poner en cuestión y reducir la autonomización y concentración actual del poder que permanece en las manos de tecnocracias financieras neoliberales. Se plantea la alternativa de una reforma que reivindique la soberanía nacional en función de las políticas populares de integración regional y que libere a los partidos del dominio mediático, que disminuya las instituciones autoritarias y construya nuevas instituciones cuidadas por los ciudadanos. Lo que implica una transformación de la sociedad política, una nueva relación entre Estado y sociedad civil, y una renovación democrática de la misma sociedad civil. Debe prevalecer el Estado de derecho, una profunda democratización de los medios de comunicación, una transformación de las actuales bases del sistema de partidos, un desarrollo de lo social. La reforma del Estado debe acabar con la inmensa pobreza y sobre todo con la gran desigualdad por medio de trabajos productivos con remuneraciones dignas. Requiere actualización y ratificación de los derechos al trabajo, a la educación, a la salud, a la vivienda, al medio ambiente sano. ${ }^{33}$ Tiene que ver con interrelaciones donde se salvaguarde la igualdad y se respeten las diferencias.

Pero nos encontramos ante una situación realmente paradójica. Ha crecido la conciencia de la necesidad de una profunda reforma democrática del Estado; aun así la parte activa de la sociedad que podría impulsarla se encuentra desilusionada, desgastada, fragmentada y pasiva. Ciertamente una auténtica reforma del Estado no saldrá de parciales arreglos entre los partidos, ni sólo de las elites. Si desde una sociedad plural y activa no se impulsa dicha reforma seguirá siendo abortada por los intereses de los poderes fácticos y por una partidocracia miope alejada de los reales intereses de las mayorías.

\section{Notas}

${ }^{1}$ Mauricio Merino, La transición votada, México, FCE, 2003. Habría que tener como antecedente que en 1994, con la irrupción del Ejército Zapatista de Liberación Nacional y con los graves conflictos internos en el partido del Estado, el gobierno aceptó introducir algunos cambios en el organismo electoral como fueron los consejeros ciudadanos en el Instituto Federal Electoral. Un año después los partidos se habían propuesto discutir una agenda que implicaba una reforma electoral, una reforma de los poderes públicos, una reforma para el federalismo y una reforma para la comunicación social y la participación ciudadana. Esto hubiera implicado la reforma del Estado, pero los partidos sólo concretaron la reforma electoral de 1996 que posibilitó primero que la oposición se constituyera en mayoría en la Cámara de Diputados y posteriormente que un partido opositor asumiera la Presidencia de la República.

${ }^{2}$ El equipo que se encargó de examinar la temática sobre derechos humanos y libertades públicas estuvo compuesto por 23 personas. En siete ocasiones tuvo reuniones plenarias. Fueron discutidos 21 puntos prioritarios en tres subgrupos de trabajo donde se presentaron 33 documentos. El equipo abocado a examinar los objetivos económicos y sociales del Estado reunió 
a 30 personas. Este grupo tuvo ocho reuniones plenarias. Se definieron 24 temas que fueron discutidos en cuatro subcomisiones, en las que se presentaron 39 documentos. Lo concerniente a la reforma de las fuerzas armadas nacionales fue estudiado por un grupo de militares del Ejército, de la Armada y de la Fuerza Aérea que asistieron por su propia iniciativa. El grupo de trabajo que reflexionó sobre la forma de gobierno y la organización de los poderes públicos se integró con 27 personas. Se reunieron en nueve ocasiones. También trabajaron en subcomisiones en las que se presentaron 45 documentos. El grupo sobre federalismo, descentralización, autonomías y municipios se reunió en siete ocasiones y fueron discutidas 27 ponencias. En el grupo que estudió reforma política y democracia participativa estuvieron 33 personas que se reunieron en sesiones plenarias siete veces y se analizaron 35 ponencias. El equipo encargado de ver la temática de constitución y globalidad, formado por 22 personas, discutió 33 documentos en nueve plenarias. Se realizaron nueve foros en los que de una u otra forma participaron 1500 personas.

${ }^{3}$ En el año 2001, publicadas por la UNAM, aparecieron las conclusiones y las propuestas de la Comisión de Estudios para la Reforma del Estado. La edición contenía además un disco compacto con todo el material.

${ }^{4}$ Muñoz Ledo recordó que cuando había presidido la LVII Legislatura de la Cámara de Diputados se había realizado una encuesta en todo el país entre juristas sobre las reformas necesarias a la Constitución, en el resultado se veía que 90\% debía ser cambiado. Recalcó que la Constitución era ya obsoleta, pese a su sacralización. El excesivo número de reformas ha alterado muchos de sus propósitos originales y ha generado incontables contradicciones que conducen a la controversia constitucional (Porfirio Muñoz Ledo, "El Estado Fallido”, en El Universal, 13 de octubre de 2005).

5 Javier Hurtado, en su escrito "El Jefe de Gabinete" (Mural, 3 de agosto de 2005) exhorta a no confundir las figuras. El jefe de Gabinete en un sistema presidencial es distinto al primer ministro de un sistema parlamentario en donde sí es jefe de Gobierno, y al Premier de un sistema semipresidencial como el francés en donde ejerce conjuntamente con el presidente de la República la Jefatura de Gobierno. El jefe de Gabinete forma parte de la estructura orgánica del Poder Ejecutivo.

${ }^{6}$ En lugar de esa indispensable comisión de verdad el gobierno del presidente Fox creó una Fiscalía Especial para Movimientos Sociales y Políticos del Pasado que resultó ineficiente. Su operación no logró juzgar ni condenar los crímenes del pasado, requisito de toda transición, y fue un subterfugio para mantener la impunidad.

${ }^{7}$ En realidad fue en esto en lo único en que hubo avance en el gobierno del presidente Fox. Se creó el Instituto Federal de Acceso a la Información.

${ }^{8}$ Pese a avances importantes en las discusiones, en 2005 las grandes empresas controladoras de televisoras y de estaciones radiofónicas impidieron una propuesta de ley que tenía en cuenta los reclamos de organizaciones de la sociedad civil en cuanto a la reglamentación de radio y televisión.

${ }^{9}$ Los temas de una reforma del Estado integral son muchos y muy variados. Aquí sólo se apuntaron los más relevantes.

${ }^{10}$ En una conferencia que impartió Francis Fukuyama en el Instituto Federal Electoral el 13 de junio de 2005 dijo que la política mexicana requería nuevas estrategias porque un gobierno dividido complicaba las negociaciones, y que el Consenso de Washington había traído muchos problemas, pues se había disminuido a tal punto al Estado que no podía enfrentar las problemas de sus ciudadanos. Siguiendo los textos de Joseph Stiglitz (El malestar de la globalización, Madrid, Taurus, 2002, y Los felices 90, Madrid, Taurus, 2003) habría que recordar que el Consenso de Washington desde 1989 planteó los dogmas de la globalización neoliberal — las políticas de estabilización y ajuste estructural comandadas por el FMI y el Banco Mundial que han liberalizado el sistema financiero han conducido a la indiscriminada apertura comercial, han obligado a privatizaciones de empresas públicas, han desregulado las actividades estatales, y restringido el gasto público, han impulsado reformas impositivas regresivas etcétera-, los cuales, de acuerdo con las demostraciones de ese autor, no sólo no han aportado prosperidad sino que han sido causantes de graves males en los países subdesarrollados. Porfirio Muñoz Ledo ha recalcado el hecho de que cuando las agencias internacionales hablan de la imperiosa necesidad de reconstruir el Estado algunas dirigencias de naciones dependientes se encuentren inmersas en concepciones y prácticas de un Estado desertor. Recuerda que las Naciones Unidas han argumentado con fundamentos que el desarrollo es inviable cuando el Estado es fallido ("El Estado fallido" en El Universal, 13 de octubre de 2005).

${ }^{11}$ Ludolfo Paramio "Reforma del Estado y reforma política" ponencia en el VI Congreso Iberoamericano de Ministros de Administración Pública y Reforma del Estado, San José de Costa Rica, 8 de julio de 2004. 
${ }^{12}$ Se pueden consultar sus artículos en el diario El Universal (www.el-universal.com.mx).

${ }^{13}$ Participación en el Foro América Latina y México: saldo y oportunidades del gobierno dividido, Fundaciones Rafael Preciado y Konrad Adenauer, 6 de mayo de 2004.

${ }^{14} \mathrm{El}$ financiamiento establecido en la legislación electoral ha sido calificado como escandaloso, pues una comparación de lo que los diversos países dan a los partidos en años electorales hace ver la gran desproporción. Argentina destina ocho millones de dólares, Costa Rica diez, Chile trece, Canadá veinte y Estados Unidos 152. En México, en el año 2006 se estima que los partidos recibirán 415 millones de dólares — 4,500 millones de pesos - Por esto se ha dicho que los partidos se han convertido en una lacra para la democracia (Sergio Aguayo, "El ezln y Alianza Cívica: Partidos fardo", en Reforma, 6 de julio de 2005).

${ }^{15}$ La propuesta de Alianza Cívica se puede consultar en www.alianzacivica.org.mx.

${ }^{16}$ Porfirio Muñoz Ledo, “Acabar con la simulación”, en El Universal, 14 de junio de 2005.

${ }^{17}$ Habermas entiende por poderes fácticos la capacidad que tienen para imponerse los intereses privilegiados (J. Habermas, Facticidad y Validez, Madrid, Trotta, 1998). Se ha hecho ver cómo en América latina los derechos fundamentales quedan reducidos a un ejercicio semántico, sometidos a los poderes fácticos. El sociólogo chileno Manuel Antonio Carretón también ha profundizado en el autoritarismo y los poderes fácticos en América Latina que obstaculizan la democracia (Manuel Antonio Carretón, La sociedad en que vivi(re)mos. Introducción sociológica al cambio de siglo, Santiago, LOM, 2000; y Manuel Antonio Carretón "Polis ilusoria, democracia irrelevante" en Revista Foro, número 22, marzo de 2003). El informe del PNUD sobre la situación latinoamericana (PNUD, Informe sobre la democracia en América L atina, Buenos Aires, Alfaguara, 2004) ha hecho ver cómo la grave crisis de la democracia en América latina se debe al predominio de los poderes fácticos. Entre estos sobresalen el poder del dinero, el poder de los medios de comunicación electrónicos, el poder de la Iglesia, el poder del narcotráfico y el poder del crimen organizado.

${ }^{18}$ Porfirio Muñoz Ledo, "El elefante moribundo", en El Universal, 26 de julio de 2005. Ver también el comentario de Alberto Aziz en su escrito "La decadencia", en El Universal, 2 de agosto de 2005.

${ }^{19}$ Fernando Cardoso, "Reforma del Estado y la gobernabilidad democrática”, Conferencia en la UNAM, 9 de junio de 2005.
${ }^{20}$ Encuentro Nacional sobre la reforma del Estado, realizado en Pátzcuaro con la participación de representantes de secretarías del gobierno federal, de instancias del gobierno estatal de Michoacán y el municipal de Pátzcuaro, del Programa de Naciones Unidas para el Desarrollo y de decenas de organizaciones de la sociedad civil, junio de 2005.

${ }^{21}$ En el informe del PNud sobre la Democracia en América Latina ya citado se plantea que una gran cantidad de ciudadanos ven que por la vía electoral se pueden cambiar a los partidos que asumen el poder formal, pero que los que mandan e imponen la agenda son los poderes fácticos, por lo que éstos siguen beneficiándose y no se resuelven las grandes carencias de las mayorías sumidas en una lacerante pobreza y en una grave desigualdad.

${ }^{22}$ Se insistió en la creación de un espacio de neutralidad situado por encima de las pugnas coyunturales en el que pudiesen interactuar todas las fuerzas políticas para lograr acuerdos de largo plazo. Muñoz Ledo ha insistido con actores económicos, sociales y con los partidos políticos en la necesidad de construir acuerdos que desemboquen en una profunda reforma del Estado (Porfirio Muñoz Ledo, "El Estado fallido", en El Universal, 13 de octubre de 2005.

${ }^{23}$ Consultar el documento titulado ACUERDO NACIONAL PARA L A UNIDAD, ELESTADO DE DERECHO, EL DES ARROLLO, LA INVERSIÓN Y EL EMPLEO que fue repartido y firmado el 29 de de septiembre en una reunión de las élites del empresariado, los medios de comunicación, los principales organismos sindicales, el mundo artístico y cúpulas universitarias en el Castillo de Chapultepec, por lo que se le empezó a llamar el Pacto del Castillo.

${ }^{24}$ Porfirio Muñoz Ledo, "Hegemonía o consenso", en El Universal, 4 de octubre de 2005.

${ }^{25}$ Quien tiene la riqueza más grande en América Latina y que ocupa el cuarto sitio entre los más ricos del mundo.

${ }^{26}$ Alberto Aziz, "La agenda políticamente correcta", en El Universal, 4 de octubre de 2005. Todos los intentos por democratizar los medios de comunicación electrónicos no han prosperado. Roberto Gutiérrez en su libro Informacióny democracia (Barcelona, Ediciones Pomares, 2005) ha señalado que los poderes fácticos en el ámbito de la comunicación han bloqueado cualquier cambio a la legislación imperante en este punto. En esta forma cualquier intento de modificación a la ley federal de radio y televisión ha fracasado (Javier Corral, "Democracia y medios públicos", en ElUniversal, 4 de octubre de 2005). 
${ }^{27}$ Porfirio Muñoz Ledo, "El Estado fallido", en El Universal, 13 de octubre de 2005.

${ }^{28}$ Porfirio Muñoz Ledo, "La ruptura pactada", en El Universal, 29 de septiembre de 2005.

${ }^{29}$ Los textos de la sexta declaración de la selva lacandona se pueden consultar en www.ezln.org.

${ }^{30}$ Se puede ver la entrevista que le hizo Carlos Antonio Aguirre Rojas, y que publicó en el libro Emmanuel Wallerstein: críticas del sistema mundo-capitalista, México, ediciones Era, 2003.

${ }^{31}$ Boaventura de Sousa Santos, El milenio huérfano, Madrid, Trotta, 2005.

${ }^{32}$ En esto concuerda Javier Osorido en su libro El Estado en el centro de la mundialización. La sociedad civil y el asunto del poder, México, FCE, 2004, quien apunta que las fracciones burguesas que hegemonizan la mundialización propician la reforma del Estado para fortalecerlo. Se busca que sea más eficiente no sólo en términos administrativos sino también en términos políticos para mantener disciplinada a la población asalariada y para reestructurar las economías a la imagen y semejanza de los intereses hegemónicos locales e internacionales. En la mente del Banco Mundial existe la preocupación de la reforma del Estado para con ello lograr mayor eficiencia en la dominación. ${ }^{33}$ Teresa Castro y Lucio Oliver (coords.), Poder y politica en América Latina, México, Siglo xxi, 2005.

\section{Bibliografía}

Acuerdo nacional para la unidad, el estado de derecho, el desarrollo, la inversión y el empleo, 29 de septiembre, Castillo de Chapultepec.

Aguayo, Sergio, 2005, "El EzLn y Alianza Cívica: Partidos fardo", en Reforma, 6 de julio.

Aguirre Rojas, Carlos Antonio, 2003, Emmanuel Wallerstein: críticas del sistema mundo-capitalista, ediciones Era, México.

Alianza Cívica, en www.alianzacivica.org.mx.

Aziz, Alberto, 2005 "La decadencia”, El Universal, 2 de agosto.

—, 2005 "La agenda políticamente correcta”, El Universal, 4 de octubre.

Cardoso, Fernando, 2005, "Reforma del Estado y la gobernabilidad democrática". Conferencia en la UNAM, 9 de junio.
Carretón, Manuel Antonio, 2000, La sociedad en que vivi(re)mos. Introducción sociológica al cambio de siglo, LOM, Santiago.

—, 2003, "Polis ilusoria, democracia irrelevante", Foro, número 22, marzo.

Castro, Teresa y Oliver, Lucio (coords.), 2005, Podery politica en América Latina, Siglo xxi, México.

Corral, Javier, 2005 "Democracia y medios públicos", El Universal, 4 de octubre.

ElUniversal (www.el-universal.com.mx).

EZLN, 2005, Sexta Declaración de la Selva Lacandona, en www.ezln.org.

Foro América Latina y México: saldo y oportunidades del gobierno dividido, Fundaciones Rafael Preciado y Konrad Adenauer, 6 de mayo de 2004.

Gutiérrez, Roberto, 2005, Información y democracia, Ediciones Pomares, Barcelona.

Habermas, J., 1998, Facticidady Validez, Trotta, Madrid.

Hurtado, Javier, 2005, "El Jefe de Gabinete", Mural, 3 de agosto.

Merino, Mauricio, 2003, La transición votada, FCE, México.

Muñoz Ledo, Porfirio, 2005, “Acabar con la simulación”, El Universal, 14 de junio.

—, 2005, "El elefante moribundo", El Universal, 26 de julio.

-, 2005, "La ruptura pactada", ElUniversal, 29 de septiembre.

—, 2005, "Hegemonía o consenso", ElUniversal, 4 de octubre.

—, 2005, "El Estado fallido" El Universal, 13 de octubre.

Osorido, Javier, 2004, El Estado en el centro de la mundialización. La sociedad civily el asunto del poder, FCE, México.

Paramio, Ludolfo, "Reforma del Estado y reforma política", ponencia en el VI Congreso Iberoamericano de Ministros de Administración Pública y Reforma del Estado, San José de Costa Rica, 8 de julio de 2004.

PNUD, 2004, Informe sobre la democracia en América Latina, Alfaguara, Buenos Aires.

Sousa Santos, Boaventura de, 2005, El milenio buérfano, Trotta, Madrid.

Stiglitz, Joseph, 2003, Los felices 90, Taurus, Madrid. —, 2002, El malestar de la globalización, Taurus, Madrid. 